\title{
Arbitragem e o Direito Comunitário: Conflitos sobre RECURSOS NATURAIS E RESPONSABILIDADE CIVIL *
}

\section{Mauricio Alexandre Kuntzler}

\section{INTRODUÇÃO}

No âmbito do direto internacional destacaremos a estrutura jurídica na Resolução de Controvérsias da OMC, da União Européia, do Nafta e do Mercosul. Estas três últimas são organizações que compõem regiões de cooperação internacional, se intercomunicam através de tratados acordos e por tratados bilaterais entre organizações internacionais e Estados estando condizentes com seus ordenamentos internos e tratados constitutivos. A profundidade da cooperação econômica faz diferenciar organizações regionais de cooperação econômica (integração comercial e aduaneira entre os Estados membros com vistas ao fortalecimento econômico e redução das assimetrias entre os Estados) e organizações regionais de integração. O Nafta e o Mercosul são organizações intemacionais de caráter intergovernamental compostas de Estados soberanos e coordenados, tendo representatividade em todos os atos decisórios das organizações sendo mediata a eficácia destas, pois sua execução é efetuada pelos Estados para possuir efeitos na ordem jurídica interna.

A união européia é uma organização internacional de caráter intracomunitário onde os Estados componentes cedem uma parte de sua soberania em proveito da organização, compondo-se a supranacionalidade ${ }^{1}$. (sentenças do TJCE, caso Costa/Enel, 1964 e caso Simmenthal, 1978) Caracteriza esta pelo fato dos integrantes dos órgãos decisórios comunitários, que atuam no interesse da Comunidade, não representarem interesses dos governos de seus Estados de Origem e pela eficácia das decisões ser imediata não necessitando ser internalizadas por qualquer ato interno dos Estados para que produzam efeitos em sua

* Trabalho apresentado na Disciplina DIRP 131- Direito Internacional Ambiental e Direito Internacional Privado.

${ }^{1}$ Martín, Areceli Mangas. Instituciones y Derecho de la Unión Européa. Madrid: Tecnos, 2002. P. 414 à 421. 
ordem jurídica interna, mesmo que contraditória a esta. Além de possuir uma norma comum para toda a comunidade a sua interpretação e aplicação é uniformizada pelo TJCE e TPI (Tratado de Nice - altera o art.225 do TCE) de forma que todos os Tribunais nacionais de forma vinculante de a mesma incidência do TCE por toda a extensão do comunidade. $\mathrm{O}$ TJCE possui a competência contenciosa e consultiva com capacidade de decidir sob o mecanismo de prejudicialidade (reenvio prejudicial) sendo um dos instrumentos desta uniformização do Direito Comunitário. O art.234 do TCE obriga a todos os tribunais dos estados membros, como órgão de última instância judicial ou de sentenças que não caiba mais recurso, a remeter questão de Direito suscitada, havendo dúvida razoável, que dependa da interpretação do TCE ou de atos adotados pelas instituições da comunidade incluindose a validade destes atos segundo o Direito originário. Aspectos materiais da causa em questão, ou seja, a decisão do mérito pertence somente a jurisdição nacional não sendo objeto de análise dos tribunais comunitários.

O trabalho visa verificar no primeiro capítulo como os conflitos entre Estados nas diferentes organizações são postos à resolução e como o direito comunitário e o direito da cooperação de blocos econômicos regionais se fundamentam diante de seus princípios embasadores de seus tratados constitutivos. Com o problema se verificará qual o direito que terá primazia na aplicação ao caso concreto, o direito comunitário, o de integração ou o direito internacional correspondente. Analisaremos no segundo capítulo a responsabilidade ambiental no âmbito da proposta de diretiva da comissão da união européia e como o bem ambiental vem sendo tratado no âmbito do Mercosul, tendo assim evidenciado os diferentes estágios e caminhos trilhados pelas organizações regionais perante o bem ambiental.

\section{A RESOLUÇÃO DE CONTROVÉRSIAS NASORGANIZAÇÕES INTERNACIONAIS REGIONAIS E NA ORGANIZAÇÃO MUNDIAL DO COMÉRCIO}

O Tribunal de Haia em 1960, no assunto das concessões Mavtommatis em Palestina, definiu a controvérsia internacional como um desacordo entre dois sujeitos sobre um ponto de Direito ou de fato, conformando uma oposição de teses jurídicas ou de interesses. Com a evolução e criação de novas Organizações Internacionais houve um incremento da morfologia de soluções de controvérsias. A evolução desta matéria trouxe o enfoque na prevenção do litígio.

As Organizações Internacionais de Cooperação e Integração Econômicas buscam, nas controvérsias entre os Estados Partes, atender os interesses destes identificando suas responsabilidades, mas sobretudo atender os interesses da Organização Internacional. Esta tarefa é dificultada quando o Direito institucional da Organização Regional de Cooperação permite ao Estado levar sua controvérsia a uma Organização Universal, portanto sob outro ordenamento jurídico do qual gerou o conflito entre os Estados. 
A arbitragem internacional, como meio legal de solução de controvérsias entre sujeitos internacionais, é um órgão unipessoal ou colegiado a que as partes se submetem por acordo estando obrigadas ao cumprimento da decisão fundamentada no Direito Internacional. Os Estados em litígio, sob a arbitragem, podem ser signatários de um acordo internacional em que haja a cláusula compromissória com obrigação de recorrer a arbitragem para a resoluções de suas controvérsias, ou são partes de um Tratado de Arbitragem (Mercosul). Devem as partes se submeterem ao compromisso arbitral, que designa o direito aplicável e o procedimento a seguir, considerando-se como fonte jurídica que indica o objeto da controvérsia e as competências dos árbritos. Podem as partes acordarem no compromisso arbitral, se assim o Tratado respectivo permitir, que a controvérsia será decidida por base da equidade tornando-se um juízo mais político que jurídico.

A supranacionalidade na União Européia condiciona e é característica do sistema jurisdicional comunitário, pois há uma ordem jurídica própria independente e hierarquicamente superior aos sistemas jurídicos nacionais. Há um poder político externo superior aos Estados e a aplicabilidade imediata do Direito Comunitário (postura monista nas relações de Direito Comunitário e Direito nacionais). A jurisprudência do TJCE consolida estes preceitos da integração européia. Casos como o Costa/ ENEL e Simmenthal II evidenciam a primazia do Direito Comunitário permitindo ao juízo nacional tornar inaplicáveis as normas conflitantes do Direito interno diante das provisões do direito comunitário. Para isto não é necessário aguardar o afastamento prévio das normas inválidas pelo órgão competente nacional sendo que o juízo nacional deverá aplicar normas comunitárias caso incidam sobre o conflito (efeito direto) ${ }^{2}$. Os Estados membros se submetem a responsabilização, pelos atos ou omissões de seus órgãos representativos, em indenizar os danos causados pela não cumprimento da norma comunitátia.

\section{a. Conflitos entre Estados na OMC, UE, NAFTA, MERCOSUL}

No Direito Internacional Econômico não se aplica a norma consuetudinária de direito internacional (séc. XVII) do esgotamento dos recursos internos na ordem jurídica do Estado reclamado (evitar a ingerência internacional, responsabilidade internacional, na medida de ser possível a busca da solução interna no Estado reclamado), podendo assim, como exemplo na OMC, o reclamante dispor dos órgãos de revisão da organização para apresentação da reclamação sem a exigência especificada.

$\mathrm{Na}$ rodada Uruguai, em 1986, surgiu a reforma do sistema de resolução de conflitos no GATT e já no âmbito da OMC surge o ESC- Entendimento Relativo às Normas e Procedimentos sobre Solução de Controvérsias- como um sistema quase judicial (painel

2 Dias, José Eduardo de Oliveira Figueiredo. Tutela Ambiental e Contencioso Administrativo. Coimbra: Coimbra, 1997. P. 111 à 119. 
estabelecido ad hoc unilateralmente onde as partes são ouvidas podendo recorrer da decisão a um órgão de apelação) criado pelo OSC (composto por representantes dos membros do $\mathrm{OMC}$ ) independente dos demais órgãos e exclusivo para este fim.

Os princípios fundamentais da OMC são o da Nação mais favorecida - qualquer vantagem concedida a um parceiro comercial estende-se aos demais membros da OMC, e o Tratamento Nacional - um Membro da OMC não pode discriminar produtos importados de outros membros da organização concedendo o mesmo tratamento jurídico dos produtores nacionais. (medidas indistintamente aplicáveis)

A OMC não é uma instância supranacional e não oportuniza um recurso a decisões nacionais em caráter prejudicial, portanto a decisão de seus órgãos não terão aplicabilidade direta (efeito direto) nos Estados integrantes e não é obrigatória, mas por haver uma maior adensamento de juridicidade, no que concerne a resolução de controvérsias, permite a ação de compensação e retaliações pelo Estado que teve êxito em sua reclamação perante o OSC.

$\mathrm{Na} \mathrm{OMC}$ não há regra de prevenção de foro, podendo ocorrer situações complexas por esta ausência de norma de competência, caso haja duplicidade de reclamações a difetentes organizações internacionais segundo mecanismos diferenciados de solução de controvérsias. No Mercosul há previsão legal no Protocolo de Olivos que prevê preventivo o foro segundo a escolha do reclamante. No entanto antes da edição do protocolo de Olivos não havia previsão legal sobre norma de competência. Situação complexa ocorreu com o litígio entre Brasil e Argentina na aplicação de medidas antidumping desta nas exportações brasileiras de frango. Pelo julgamento do tribunal arbitral do Mercosul (protocolo de Brasilia) a medida foi considerada legal. No entanto o Brasil, após a decisão do laudo arbitral, interpos reclamação na OMC revertendo a decisão, pela incompatibilidade entre a medida argentina e o acordo antidumping.

A diferença no aspecto da implementação das decisões dos órgãos de soluções de controvérsias do Mercosul, Nafta e OMC, está em que, no âmbito do Mercosul, as decisões são obrigatórias (art. 26 e 27 do Protocolo de Olivos) atribuída efeitos de coisa julgada.

O sistema de resoluções de controvérsias do Nafta (Organização internacional regional de cooperação econômica exclusiva, não se pensou em uma comunidade política) possui a arbitragem entre Estados membros e a arbitragem específica para o conflito entre o estado Membro e o Investidor admitindo-se a compensação por perdas monetárias e a execução da decisão do painel por tribunais nacionais de execução sob a Convenção de Nova York ou Interamericana. Faculta aos Estados utilizarem o sistema do Nafta ou da OMC para resolverem seus conflitos. No que tange ao meio ambiente não é facultado a escolha seguindo o procedimento constante no Nafta. O painel pode valer-se de especialistas para a elaboração de parecer técnico. Em matéria referente a medidas anti-dupmping e direitos compensatórios a decisão do painel binacional de revisão será vinculativa aos Estados.

O caráter intergovernamental do Mercosul impossibilita a criação de um Tribunal de Justiça supranacional. O Conselho do Mercado Comum não assentou politicamente nesta direção e por outro lado necessário se faz mudanças constitucionais no Brasil e no Uruguai 
(falta de delegação de competências para órgãos legiferantes e jurisdicionais). Com o protocolo de Olivos se instituiu o recurso de revisão ao Tribunal Permanente de Revisão. As controvérsias que surjam entre os Estados-partes serão decididas a base do Direto Primário, o Direto Derivado e princípios do direito internacional. O objeto da controvérsia deverá ser fixado na etapa das negociações diplomáticas não podendo ser modificado posteriormente pelas partes.

O Estado-parte poderá interpor reclamação perante outro órgão de resolução de controvérsias do que aquele instituído ad hoc no plano do Mercosul. Poderá demandar perante o OSC da OMC ou utilizar outro foro contido em determina acordo econômico bilateral ou regional onde façam parte os integrantes do Mercosul. Neste caso porém, uma vez iniciado o procedimento de reclamação sob determinado mecanismo de solução de controvérsias, não haverá mais a possibilidade de se utilizar de outro mecanismo, sob o mesmo objeto, composto em outro acordo. No caso de o OSC da OMC ser escolhido pelo demandante para a resolução de conflitos do âmbito do Mercosul, a atuação do Grupo Especial e o OAp será restrita ao âmbito da legalidade da medida analisada sob a ótica das leis multilaterais da Organização, não se manifestando sobre a legalidade sob as normas vigentes no âmbito do Mercosul.

O Protocolo de Olivos permitiu ao Tribunal Arbitral Ad Hoc, por solicitação da parte interessada, sob a possível ocorrência de danos graves e irreparáveis, ditar medidas provisórias para prevenir prejuízos. Permitiu também, ao Conselho do Mercado Comum, estabelecer procedimento especiais para casos de urgência com intuito de não causar danos graves as partes.

A inovação oportunizada pelo protocolo de Olivos é a competência ao Tribunal em decidir diretamente sob casos onde fracassaram as negociações diretas atuando como instância única. Terá também competência para responder às opiniões consultivas formuladas pelos órgãos do Mercosul, Estados-partes e seus Tribunais Superiores de Justiça, tendo que esta opção deva ser regulamentada pelo Conselho Mercado Comum estabelecendo o procedimento. Não terá efeito vinculante o parecer.

No direito comunitário europeu a norma comunitária e o regulamento devem ter aplicabilidade imediata no Direito nacional e passível de ser invocada por pessoas privadas nas jurisdições nacionais ainda que não internalizadas (aplicabilidade direta) quando são formuladas sem reservas, sejam auto-suficientes e juridicamente perfeitas, e não necessitam de qualquer ação dos Estados membros ou da Comissão para a sua execução. O regulamento, por sua própria natureza (art.249 TCE), possui as características elencadas acima. A diretiva, se também possuir caráter "self-executing" e que o prazo para sua transposição pelo Estado membro tenha se esgotado, é diretamente aplicável no Direito Nacional. ${ }^{3}$ A decisão, por sua

Idem. P.120. O autor faz referência a Rui Manuel Moura Ramos "Das Comunidades à União Européia" p.227, para citar o Acórdão Francovich do TJCE, que precisa caber aos Estados membros indenizar aos particulares pelos prejuízos causados devido a não transposição de diretiva que reconheça direitos e tenham nexo de causalidade com o danos sofridos. 
vez, quando dirigida ao Estado membro e atender os mesmos requisitos para a aplicabilidade direta da diretiva, terá os mesmos efeitos. A decisão quando individualizada e dirigida ao particular possuem também efeito direto. Não havendo a aplicabilidade direta pelo juízo nacional da norma comunitária deverá o agente privado dirigit-se a Comissão das Comunidades e convencê-la a iniciar uma ação por incumprimento do Tratado contra o Estado responsável pela violação de seus direitos, isto na qualidade de guardiã da legalidade comunitária.

O TJCE tem a função de interpretar o Direito Comunitário como um todo e a função do controle de sua aplicação. Interpteta o Direito derivado conforme o Direito Primário assegurando a capacidade de ação dos órgãos comunitários e a unidade sistêmica do ordenamento jurídico comunitário sendo elemento chave na concretização dos objetivos do TCE. Atua sobre litígios entre as instituições comunitárias, entre os Estados Membros, entre os Estados membros e as instituições comunitárias e entre as pessoas privadas e os Estados ou instituições comunitárias. (recurso por ilegalidade que deriva o recurso de anulação, art.230TCE e recurso por omissão art232TCE). Sua atuação é através de consultas jurídicas vinculantes sobre Acordos que a EU celebra com Países terceiros ou Organizações Internacionais e na própria interpretação e aplicação do Direito Comunitário.

O Tribunal de Primeira Instância surge do A to Único Europeu de 1988, por decisão do Conselho, atuando na mesma função do Tribunal de Justiça, órgão garantidor de interpretação e aplicação do Diteito Comunitátio.

\section{b. A Natureza da OMC e da EU, o Efeito Direto e Controle Prévio dos Acordos Internacionais}

É previsto no att. 300, n. 6 do TCE, o controle preventivo exercido pelo TJCE de constitucionalidade dos possíveis atos internacionais da Comunidade em referência das disposições do direito material, à competência, ao procedimento ou a organização institucional da Comunidade, utilizando-se para isto de pareceres vinculantes, anteriores aos atos ou mesmo posteriores a eles. Para que o acordo se efetive, etn caso de parecer contrário, deverá haver uma prévia revisão do Tratado comunitário e ratificado pelos estados membros.

A posição formal hierárquica dos acordos situa-se entre o Direito Comunitário primário e o Direito Comunitário secundário.

Após a edição do acordo poderá o TJCE anulá-lo pelo recurso interposto pelo Estado membro interessado, contestando sua legalidade perante o Direito Comunitário. Esta decisão porém terá somente validade para a Comunidade Européia e não para o Direito Internacional. Neste sentido, conforme a Convenção de Viena sobre o Direito dos Tratados entre Organizações Internacionais e Estados ou entre Organizações Internacionais entre si (arts. 28 e 46-1986), caberá a responsabilidade internacional a Comunidade Européia que tornou internamente sem efeito o Tratado celebrado. 
O TJCE pronunciou-se na sentença "Kupferberg" de 1982 que nos acordos internacionais,

$$
\begin{aligned}
& \text { "os efeitos... não podem ser examinadas abstraindo-se a } \\
& \text { origem internacional destas disposições..., de acordo com os } \\
& \text { princípios de Direito Internacional as instituições comunitárias } \\
& \text { são livres para decidir... os efeitos que as disposições do acordo } \\
& \text { devam produzir no ordenamento interno das partes } \\
& \text { contratantes."4 }
\end{aligned}
$$

Mas caso no acordo não exista esta previsão quanto aos efeitos das disposições, caberá analisar, quanto as suas características do acordo, a sua natureza, e se contém obrigação clara, precisa e incondicionada não necessitando de ato posterior para a execução da medida (self-executing). Portanto, nesta situação, os particulares dos Estados membros podem invocar as disposições do acordo perante os Tribunais nacionais.

Mesmo que a Comunidade Européia seja composta por membros fundadores da OMC o TJCE nega a aplicabilidade direta dos acordos GATT e posteriormente da OMC não fundamentarıdo o direto de ação de particulares contra órgãos comunitários. Conforme decisão do Conselho a natureza do acordo que instituiu a OMC não pode ser invocado diretamente nos tribunais da Comunidade e dos Estados-membros, pois o GATT e posteriormente a OMC baseia-se no princípio das negociações realizadas numa base de reciprocidade e de vantagens mútuas diferenciando da Comunidade, sendo que acordos com esta pode possuir assimetria de obrigações.

“...a posição do Tribunal é de que os acordos OMC não visam criar direitos a particulares, mas limitam-se a regular as relações entre Estados e Organizações econômicas regionais com base em negociações que assentam no princípio da reciprocidade." 5

No caso Portugal contra Conselho, 1999, objeto Decisão 96/386/CE, reafirma que o acordo da OMC e seus anexos não configuram, em princípio, entre as normas tomadas em conta pelo Tribunal de Justiça para fiscalizar a legalidade dos atos das instituições comunitárias. O Tribunal declata que só caberia fiscalização dos atos comunitários com referência as disposições da $\mathrm{OMC}$ se a violação fosse reconhecida pelos órgãos da $\mathrm{OMC}$ e que a Comunidade tivesse comprometido a executat as recomendações e decisões do Órgão de Resolução de Controvérsias.

4 KLOR Adriana Dreyzian, PIMENTEL Luís Otávio, KEGEL Patrícia Luiza, BARRA Welber. Solução de Controvérsia - OMC, União Européia e Mercosul. Konrad-Adenauer-Stifting, RJ, 2004, p.124

s Idem, p. 126 


\section{Análise do caso Biret, sentença do TJCE de Setembro de 2003}

Em 1996 o Conselho adotou a da Diretiva 96/22/CE proibindo a utilização de certas concentração de substâncias com efeitos hormonais $\epsilon$ de substâncias beta-agonísticas em produção animal, e a importação de produtos com tais concentração de substâncias. Em 1998 o OSC da OMC declarou o regime comunitário incompatível com o acordo SFS (Acordos relacionados à aplicação de medidas sanitárias e fitossanitárias) e concedeu prazo à Comunidade para executar sua decisão. Em 2000 a Biret Internacional SA ingressou ação contra o Conselho (art.235 e 288 TCE) requerendo o ressarcimento do dano causado pela manutenção da Diretiva 96/22 e portando a proibição de importação de carnes e derivados com hormônios dos EUA. O TPI e o TJCE julgaram improcedente a ação e reiteram suas posições de que os acordos da OMC quanto às decisões de seu OSC são baseados em negociações que assentam no princípio da reciprocidade, ou seja, a não execução de uma decisão do OSC é considerada como sendo uma opção de política comercial e não de opção jurídica ${ }^{6}$. Assim não produzem efeitos intracomunitários., pois a decisão do OSC não é um parâmetro válido para verificar a legalidade dos atos comunitários e a Comunidade em nenhum momento assumiu o compromisso de dar execução as obrigações decorrentes da decisão da OSC.

A apresentação destes casos referenciais se destina a visualizar que na União Européia a política ambiental empregada desde a Ato Único Europeu de 1986 juntamente com princípio embasador da solidariedade possibilita ao direito comunitário ser referência exclusiva para as decisões do TJCE referente a matéria ambiental não sendo contaminado por disposições internacionais, no qual não se adere por acordo, contrárias as suas normas do direito originário e derivado. O Mercosul ao alcançar o seu objetivo de mercado comum dentro das evoluções necessárias, com política e legislações ambientais próprias, poderá não somente proteger o bem ambiental por exceção conforme disposto no art. $2^{\circ}$, letra b do Anexo I do seu tratado constitutivo. O Nafta por sua vez não tem a pretensão de obter um mercado comum a não ser uma zona de livre circulação de mercadorias e a harmonização de legislação ambiental pretendida entre os Estados membros se destina principalmente a não ocorrência de discriminação de produtos importados diante dos nacionais e não propriarnente uma proteção ambiental efetiva.

\section{II . A RESPONSABILIDADE AMBIENTAL}

A responsabilidade ambiental, no Direito brasileiro estabelecida pela Lei 6938/81, se consubstancia pela obrigação do poluidor de indenizar e reparar os danos produzidos ao ambiente e ao terceiro independente de culpa. É a responsabilidade estrita instituída no Direito Ambiental. (art. 14). A doutrina especializada (José Rubens Morato Leite) atribui a inversão do ônus da prova, diante um processo que vise constituir a responsabilidade, pela

${ }^{6}$ Idem, p. 134 
aplicação do princípio da precaução localizado na Constituição no art. 225, parágrafo $1^{\circ}$, inc. IV. No entanto, esta possibilidade legal da inversão do ônus da prova estaria restrita a atividades potencialmente causadora de significativos impactos ambientais a ser visualizado em um estudo prévio (EIA). Há no Direito do Consumidor um princípio geral da hipossuficiência atribuída ao consumidor, instituindo assim a possibilidade ao juiz inverter o ônus da prova. No direito ambiental temos a hipossuficiência geralmente atribuída a parte por não ter condições técnicas de comprovar o nexo de causalidade entre o dano e a atividade poluidora. Caberá ao agente, que possui as informações técnicas de seu empreendimento, de esclarecer em juízo não ter relação com o específico dano ambiental. ${ }^{7}$

A responsabilidade civil diante do bem ambiental deve ser visualizada ao interesse de todos e não pelo sistema clássico visando o indivíduo para sua indenização, pois este bem não é suscetível de apropriação exclusiva por ser de interesse público, de característica difusa e titularidade comunitária. Neste sentido a abrangência do instituto da responsabilidade ambiental deve possuir guarida a aplicação dos princípios da precaução, prevenção e do poluidor-pagador. A incidência dos princípios da precaução e prevenção está na devida distribuição do ônus da prova e celeridade processual (tutela inibitória, acesso a justiça), e no ressarcimento efetivo (evitar a fraude- problema de empresas satélites que não tenham recursos para reparar o dano) ao bem ambiental degradado justificado pela incidência do princípio da proporcionalidade de forma a inibir o agente a poluir o ambiente. O princípio do poluidor pagador perfaz o caminho do pagamento pelo agente da poluç̧ão causada, mas não se isenta com este ato a responsabilidade devida ao danos causados a biodiversidade e ao homem. $O$ princípio é também utilizado diante das relações comerciais internacionais para que o exportador internalize os custos no preço do produto para a proteção ambiental como, por exemplo, em investimentos tecnológicos de mitigação do dano. A inserção dos custos ambientais ao preço não caracteriza o subsídio em uma concorrência desleal.

Em vista dos danos ambientais não estarem conscritos na sua dimensão ao território dos Estados deve-se haver uma ação conjunta dos Estados que compõe um bloco comercial de integração. Necessário será uma política ambiental comum e a construção na obtenção de uma harmonização legislativa ambiental com intuito de uma proteção efetiva e de evitar discriminação disfarçada de produtos importados frente aos nacionais em relação a proteção ambiental.

\section{a. Aplicação da Responsabilidade Ambiental na UE - Diretivas e harmonização das legislações}

A União Européia possui um política comunitária ambiental que começou a se desenvolver desde que as razões de união dos Estados foram puramente econômica,

7 Dallagnol Junior, Antônio Janyr. Distribuição Dinâmica dos Ônus Probatórios. RT-788, 2001. Cita a Teoria das Cargas Processuais Dinâmicas desenvolvida pelo Argentino- Jorge W. Peyrano) 
maximizada em termos de eficiência de forma a julgar a proteção ambiental como diminuição de custos sociais de produção da empresa. O meio ambiente faz parte da análise econômica deixando de ser visto como uma externalidade. Foi na década de 60 que se instituiu a primeira diretiva ambiental, $\mathrm{n}^{\circ} 67 / 548$ - sobre Classificação, etiquetagem e embalagem de substâncias perigosas. Com o Ato Único Europeu, em 1986, se reconhece a competência comunitária na área ambiental lhe outorgando a base jurídica para exercer a política do meio ambiente. ${ }^{8}$ Desde então muitas diretivas foram editadas para disciplinar temas ambientais com fundamento do então art. 100 (art.94 TCE) com objetivo de regular a matéria mínima e aproximar disposições legislativas e adłninistrativas nacionais. (art.2 ação ambiental necessária para atingir o objetivo comunitário desejado, ou seja, de um desenvolvimento harmonioso das atividades econômicas)

A natureza jurídica da diretiva é questionada em relação ao efeito que produz no ordenamento jurídico nacional dos Estados membros. Além da aplicabilidade direta (a incorporação da diretiva no direito interno dispensa qualquer ato de recepção do Estado) a diretiva tem a potencialidade de ter efeito direto ,podendo ser invocada pelos particulares nos seus Estados membros diante do tribunal contra atos administrativos e legislativos contrários. Este entendimento foi construído pelos julgados do TJCE (caso Costa/Enel,1964, Francovich/1991) já que o art. 249 do TCE só especifica o regulamento e a decisão como atos diretamente aplicáveis nos Estados membros. O TJCE dentre seus julgados estabelece condições para que a diretiva produza efeitos diretos: as disposições devem ser claras, precisas, completas e incondicionadas de forma que atribua direitos e obrigações, dispondo o seu conteúdo e o âmbito de alcance. A consequência desta interpretação é o aumento de efetividade do direito comunitário transpondo sua supremacia ao Estado membro e constituindo a determinadas diretivas o efeito direto vertical independentemente de qualquer ato legislativo regulamentar nacional no sentido de sua efetivação.

O Estado que não transpor a diretiva ambiental, por ser contrária ao direito nacional, sofrerá a sanção de indenizar os danos decorrentes desta não transposição aos particulares. Há o nexo de causalidade entre o dano sofrido dos particulares e a omissão do Estado do dever de transposição. Essta possibilidade poderá ser admissível e comprovada pelo reenvio prejudicial, instituto que permite ao indivíduo pedir que o órgão judiciário nacional (em caso de ser última instância o órgão tetá a obrigação de fazê-lo) requeira ao TJCE que se pronuncie sobre determinada interpretação do tratado e sobre a validade dos atos adotados pelas instituições da Comunidade.

Para abordarmos da harmonização das legislações nacionais, o qual as diretivas se propõe, é necessário também fazer uma análise do art. 30 TCE que refere-se a possibilidade do Estado membro exercer seu direito de fazer atos contrários ao princípio da livre circulação

8 Dias, José Eduardo de Oliveira Figueiredo. Tutela Ambiental e Contencioso Administrativo. Ciombra: Coimbra, 1997. P.98 à 103. 
de mercadorias justificadas por razões de ordem pública (origem art. XX do GATT). Se discute se as razões apresentadas no art. 30 são exaustivas (numerus clausus) ou se na medida da evolução dos problemas estatais poderia acrescentar outras exceções. Outra tema controverso é se as exigências imperativas estatais poderiam se encontrar também sob o marco do art.30, fazendo exceção ao art.28 ou se deveria atuar diretamente sob o conceito de medida de efeito equivalente para enquadrá-lo ou não ao previsto neste artigo. Com a evolução da jurisprudência do TJCE a Dra. Nicole Vallonton entendeu que tanto as exceções acrescidas às razões de ordem pública (proteção ao meio ambiente e ao consumidor) são incluídas no art. 30 como também as exigências imperativas estatais estaria sobre a sua configuração.

“... Según se desprende dela evolución jurisprudencial, el próprio TJCE de facto esta utilizando los mismos critérios para examinar las medidas en función de los objetivos del art. 36 o de los nuevos objetivos estatales considerados como exigencias imperativas. En efecto, tales objetivos tienen el mismo origen, lamisma razón de ser y siguen los mismops criterios de aplicación."”

$\mathrm{O}$ art. 30 do TCE poderá ser invocado para que o Estado-membro possa atuar subsidiariamente a diretiva e propor medidas mais restritivas que a disposição comunitária. Assim acontece com a Diretiva 88/407 que concerne os intercâmbios intracomunitários e as importações de espermas congelados de animais de espécie bovina. Esta diretiva é incompleta e permite aos Estados validamente invocar tazões sanitárias para obstaculizar a livre circulação de espermas bovinos sempre que esta restrição guarde proporção com o objerivo perseguido e seja esta a opção mais adequada. Esta foi também a interpretação do TJCE, sob o envio do Tribunal Penal da Diamarca, em relação ao assunto " $D$. Bluhme ou abelha parda de Laeso, Apis mellifera mellifera "10 pois entendeu na sentença de 3 de Dezembro de 1998 a legitimidade do governo dinamarquês de instituir um Decreto provindo do Ministério de Agricultura proibindo a criação e importação de abelhas que não pertencem a subespécie Apis mellifera mellifera em Laeso e locais arredores. Justificou sua decisão pela incidência do então art. 30 do TCE em razão da proteção da biodiversidade garantindo a subsistência da abelha específica efetuando para isto a análise da necessidade e proporcionalidade da medida em relação ao seu objetivo, o qual entendeu apropriada.

O art. 94 especifica que o nível de proteção do meio ambiente ao mercado interior, proposto pela Comissão através de diretiva visando a harmonização de legislações, deverá ser elevado tendo em conta as novidades científicas. Caberá ao Estado membro notificar a

- Vallotton, Nicole Stoffel. La Probibición de Restricciones a la libre Circulación de Mercancías en la Comunidad Europea. Madrid, Dykinson, 2000. P. 755

${ }^{10}$ Idem, p. 702 à 704 . 
Comissão das disposições nacionais mais restritivas relativas a proteção do meio ambiente ou outras razões de ordem pública mencionadas no art. 30, que deseja manter, a que pese as regras de harmonização. A Comissão analisará as disposições nacionais sob o critério de proporcionalidade e adequação de tais medidas de acordo com o fim pretendido. A decisão da Comissão é uma autorização que da efeito constitutivo e condição da aplicabilidade das disposições nacionais mais restritas. Por outro lado o art. 176, contido no Título do Meio Ambiente, permite a proteção ambiental mais restritiva pelo Estado membro do que disposiçōes comunitárias tendo como obrigação somente a notificação à Comissão.

A Comissão da União Européia instituiu o Livro Branco sobre responsabilidade ambiental ${ }^{11}$ com o objetivo de impor responsabilidades às partes cujas atividades contenham riscos de provocar danos ambientais significativos coordenado pelo princípio do poluidor - pagador. Não atuará sobre danos ambientais dispersos e difusos pela impossibilidade de correlacionar efeitos ambientais com as atividades de determinados agentes poluidores.

O objetivo primeiro da responsabilidade civil é que o causador do dano ambiental internalize os custos ambientais, pois os poluidores reduziram os danos ambientais até o ponto em que o custo marginal da sua atenuação seja superior à compensação que evitam pagar. Ocorrerá nesta medida que o empreendedor faça investimento em tecnologias para a prevenção dos riscos e de diminuição de dano ambiental (atuação do princípio da prevenção dentro de uma lógica do mercado).

Os regimes estatais da responsabilidade civil são apenas operacionais quanto aos danos à saúde humana ou ao patrimônio (danos tradicionais), e de zonas contaminadassolo, águas superficiais e subterrâneas. Não o são aplicáveis aos recursos naturais. Há já no Direito Comunitário as Diretivas, "Aves" e "Habitats", que designam zonas protegidas da rede Natura $2000 \mathrm{em}$ área de até $10 \%$ do território comunitário havendo previsão a que os Estados membros apliquem a responsabilização pelos danos causados pelos poluidores. A aplicação da Diretiva de responsabilidade ambiental permitirá criar uma situação de igualdade nas condições de concorrência do mercado interno intracomunitário. Necessário se faz que todos os Estados membros abrangem a responsabilidade sobre os danos causados a biodiversidade para não infringir-se o princípio de igualdade no marco competitivo das empresas.

Poderá ocorrer que a área protegida sob a legislação da biodiversidade faça parte de uma zona contaminada. Neste caso ocorrerá dois danos ambientais a ser reparados. Primeiramente é feito a descontaminação da área e após deverá ocorrer a restauração dos recursos naturais.

$"$ Visa melhorar a implementação dos princípios ambientais constantes no Tratado da CE. Apresentado pela Comissão em 2000 e motivada pela Resolução do Parlamento Europeu requerendo uma diretiva comunitária. 
Propugna a Comissão que a Diretiva ambiental atue também sobre os danos(habitats, fauna selvagem e espécies de plantas) significativos (Diretiva Habitats) à biodiversidade. Incide a responsabilidade objetiva referente a atividades perigosas e responsabilidade subjetiva referente as atividades não perigosas, sendo que caso não seja comprovado a culpa do agente caberá ao Estado a responsabilidade de reparar os danos causados.

Há o instrumento de avaliação de danos a biodiversidade- Inventário de Recursos para Avaliação Ambiental utilizado quando os danos causados a biodiversidade são irreparáveis. Para a avaliação do dano utiliza-se a análise custo-benefício formulada pela função da utilização previsível dos recursos danificados sob o princípio da razoabilidade caso a caso, e os custos de restauração. Caso não seja possivel a restauração deve-se basear-se a avaliação pelo custo de soluções alternativas visando a instalação de recursos naturais equivalentes.

O Livro Branco traz a preocupação quanto a responsabilidade pela limpeza de zonas contaminadas recair sobre empresas satélites de pequeno capital social integralizado (ocorre a delegação das atividades de produção arriscadas das empresas maiores) tornando--se insolvente caso ocorra danos em grande proporção. Há necessidade de as empresas se protegerem contra os riscos de responsabilidade civil por meio de seguros específicos para este fim de forma que haja para o sistema a segurança financeira exequível. A gama restrita das atividades perigosas e limitação aos danos significativos permitem contribuir para tornar os riscos suscitados calculáveis e assim maior transparência ao regime de responsabilidade. Nos EUA há a legislação federal criadora do Superfund (1980) para abranger a responsabilidade pela limpeza de zonas contaminadas por resíduos tóxicos. Tem o EPA (Environmental Protection Agency- Agência de Proteção do Ambiente) como administradora do superfundo. Caso o responsável pela contaminação não promova a descontaminação o EPA pode se utilizar do dinheiro do fundo para promover a limpeza do solo tendo direito de ação regressiva. No Brasil há o Fundo de Defesa dos Direitos Difusos - FDD, criado pela Lei 7347/85 e regulamentado pela Lei 9008/95.

A eficácia da responsabilidade pelos danos ambientais estará atrelada da capacidade das autoridades administrativas e dos juízos em resolver os processos de forma expedita e de adequados meios de acesso a justiça. (sistema judicial processual oferecer a tutela antecipada e tutela inibitória ressarcitória para fins de obrigação específica)

O regime comunitário, por motivos de segurança jurídica, funciona prospectivamente de forma que a responsabilidade civil instituída pela diretiva atuara somente sob danos ambientais ocorridos sob o âmbito de sua vigência, ou pelo prazo concedido para o Estado harmonizar sua legislação.

Haverá a divisão do ônus da prova e não a sua inversão no regime de responsabilidade ambiental.

Em princípio não se admite como causa de justificação os danos causados por emissões autorizadas das regulamentações comunitárias. Quando o operador provar que o dano ocorrido foi devido exclusivamente a emissões autorizados na licença de operação e 
atuou de forma coerente para evitá-lo, o ressatcimento não será para ele total, cabendo a autoridade que concedeu a licença parte da compensação devida. Aplicação da equidade.

Em referência as empresas públicas e privadas não recairá a responsabilidade ambiental na pessoa gestora da empresa e sim na pessoa jurídica em si.

Há convenções e protocolos internacionais que tratam da responsabilidade ambiental. Convenções sobre danos causados por atividades nucleares, convenção sobre poluição marinha causada por hidrocarbonetos e convenções sobre danos causados pelo transporte marítimo de substâncias perigosas e tóxicas. Todas baseadas na tesponsabilidade objetiva mas limitadas no valor. Assim o regime comunitário em matéria de responsabilidade ambiental será um regime complementar para as áreas que já se encontram regidas pelo direito internacional.

A Comissão entende que os problemas transfronteriços são resolvidos de modo mais eficaz a nível comunitário e não através de um regime exclusivamente transfronteriço comunitário. Nesta situação não ocorreria a incidência do princípio de igualdade de tratamento já que há países europeus que não integram o dano a biodiversidade sob o regime da responsabilidade ambiental.

São duas as justificativas para a elaboração de uma diretiva sobre responsabilidade ambiental. A primeira é o âmbito que oferece a diretiva em telação aos danos a biodiversidade em harmonia para todos os Estados membros. A Segunda é a segurança jurídica proporcionada pela diretiva comunitária que é maior em relação a Convenção de Lugano, esta não exige a adoção de medidas de reparação e não dá critérios para avaliação do dano ambiental (é a Convenção do Conselho da Europa de 1993 da responsabilidade civil por danos ambientais ocasionados por atividades perigosas - âmbito aberto e vago na área da biotecnologia, substâncias perigosas e resíduos causando insegurança jurídica- alguns Estados membros não pretendem assiná-la como Dinamarca, Alemanha e Reino Unido) oferendo tegrar e princípios ambientais em coordenação aos objetivos da Comunidade e como referência a novos integrantes possíveis a ingressar no UE.

A diretiva específica não propõe regular um segmento específico setorial (biotecnologia) pois não asseguraria um sistema coerente a aplicação igual dos princípios ambientais a atividades que são comparáveis na medida que apresentam riscos para o homem e ao ambiente. O melhor sucedido é a aplicação de um regime hotizontal de responsabilidade ambiental e não setorial. A aplicação da diretiva pela Comissão e TJCE deve ser coerente em toda a Comunidade.

A diretiva se justifica pelo princípio da subsidiariedade em relação a lacuna existente em Estados membros que não disciplinaram a responsabilidade pelo dano a biodiversidade sendo base jurídica aos tribunais nacionais para aplicar seu preceito. No que se refere ao princípio da proporcionalidade cada Estado membro utilizará os instrumentos que possui a situações específicas para atingit os objetivos da diretiva e resultados que vislumbra. A diretiva atendendo estes princípios poderá ser um regime-quadro contendo requisitos mínimos essenciais a ser graduados com a experiência pela aplicação. (TJCE) 


\section{A proposta de diretiva do Parlamento Europeu e do Conselho de 01/ $2002^{12}$ relativa à responsabilidade ambiental, encaminhada pela comissão, determina,} na exposição de motivos, em atenção aos princípios da proporcionalidade e subsidiariedade, que o Estados membros possam utilizar dispositivos institucionais e processuais concretos para se alcançarem os resultados prescritos pela diretiva.

A responsabilidade de reparação do dano ambiental compete ao Estado membro e ao agente causador do dano. Se o Estado promover a reparação, a autoridade competente, em conformidade com o princípio do poluidor pagador, deverá cobrar os custos de reparação dos operadores tesponsáveis.

O anexo I compõe-se de atividades integrantes da Diretiva potencialmente causadoras de dano ambiental. Operadores de atividades não incluídas no Anexo I pode ser responsável, ao abrigo da diretiva, pela reparação ao dano a biodiversidade se comprovar a sua culpa.

Há a responsabilidade do Estado pelo dano ambiental produzido pelo agente insolvente em restaurar o meio ambiente ou quando não seja possível visualizar o agente causador do dano.

A Diretiva não se aplica a danos ambientais que estiverem relacionados a autorização concedida pela autoridade competente ou emissões autorizadas por disposições legislativas. Neste caso o Estado-membro deverá garantir a reparação. Também não se aplica se o dano ambiental foi causado por emissões ou atividades não considerada prejudiciais pelos conhecimentos científicos na época da ação respectiva. Em relação aos danos ambientais causado por poluíção de caráter difuso, sendo impossível estabelecer uma relação causaefeito, a diretiva não terá incidência.(art.9) Caso a autoridade possa estabelecer com suficiente grau de probabilidade a identificação de diversos agentes causadores de determinado dano ambiental , caberá a ela designar o custo proporcional em termos de responsabilidade solidária. Caberá ao agente provar a parte do dano que lhe corresponde a sua atividade e suportar somente o custo relativo. (art. 11)

A prevenção será exercida pela diretiva quando proporcionar a efetiva reparação e quando o agente diante do caso concreto verificar que no seu empreendimento necessite medidas preventivas visando inibir possível risco de dano ambiental, ou mesmo quando seja exigido este conhecimento do agente. Caso não cumpra com esta obrigação de agir estará diante da responsabilidade por omissão tomando o Estado membro esta atitude preventiva. (art. $4^{\circ}$ ).

A prescrição de 5 anos do direito de ressarcimento do dano ambiental começa a contar a partir de qualquer medida efetuada pela autoridade relacionada a Diretiva em relação ao dano. $\left(12^{\circ}\right)$

${ }^{12}$ A Comissão das Comunidades Européias, após intenso debate, submete a proposta de um sistema comunitário global de prevenção e reparação dos danos ambientais ao órgãos responsáveis para analisá-la. 
As pessoas afetadas pelo dano ambiental podem pedir a autoridade a intervenção sobre o dano, e sendo pré-requisito para interpor perante um tribunal o controle da legalidade das decisões, atos ou omissão da autoridade competente.

A presente Diretiva não impede os Estados-membros de manterem ou adotarem disposições mais rigorosas em relação a prevenção e à reparação de danos ambientais. (art.18)

A autoridade competente poderá verificar com certa plausibilidade e probabilidade que o dano ambiental foi causado por uma atividade específica depois da data de cumprimento da diretiva, ou seja, 30.06.2005. cabendo o ônus de prova do agente para verificar o contrário. (art.19).

\section{b. A Realidade Ambiental no Mercosul e o laudo arbitral dos pneus recauchutados}

A proteção ambiental está prevista no Tratado de Assunção, tratado instituidor do Mercosul. No seu preâmbulo aborda a proteção ambiental prevendo sua preservação e como condição para o desenvolvimento econômico. Faz portanto parte integrante do Tratado e permite sua invocação quando não atendido este princípio jurídico. Em parte também há previsão da proteção ambiental no Anexo I do Tratado, art. $2^{\circ}$ item "b" quando menciona que o Estado poderá efetuar medida que restrinja o comércio quando previstas situações do art. 50 do Tratado de Montevidéu de 1980, medidas que protejam a saúde e vida das pessoas (forma indireta de proteção) e dos animais, e preservação dos vegetais.

O Tratado sobre Cooperação em Matéria Ambiental foi celebrado pelos quatros países integrantes do Mercosul em 1992 que prioriza a prevenção e informação sobre os danos ambientais em áreas transfonteiriças. $\mathrm{O}$ art. $4^{\circ}$ criou uma Comissão de Cooperação em Matéria Ambiental com fins de harmonizar as legislações ambientais do Estados partes. ${ }^{13}$

O Mercosul, enquanto fase de cooperação econômica, dispõe de um foro específico para discussão de questões envolvendo matéria ambiental. É o trabalho efetuado pelo REMA (Reunião Especializada de Meio Ambiente) que foi transformada no $6^{\circ}$ Subgrupo de Trabalho de Meio Ambiente (SGT) cuja função é auxiliar ao Grupo Mercado Comum no objetivo de integração. O SGT-6 teve como atribuição analisar as restrições não-tarifárias relacionadas ao meio ambiente, competitividade e meio ambiente, gestão ambiental sistema de informação ambiental, certificação ambiental comum. Analisou também a legislação ambiental dos países membros com o fim de harmonizar as políticas ambientais e normas ambientais. Por via da Resolução GMC 10/94 foram aprovados as diretrizes básicas em matéria ambiental para se elaborarem um início de harmonização com o objetivo de estabelecer critérios, paradigmas permitindo aos Estados flexibilizar a incorporação desta futura norma

${ }^{13}$ Basso, Maristela. Livre Circulação de Mercadorias e Proteção Ambiental no Mercosul. In. Mercosul: Seus Efeitos Jurídicos, Econômicos e Políticos nos Estados-Membros. Porto Alegre: Livraria do Advogado. 1997. P. 411. 
obrigatória. No entanto apesar a haver previsão de harmonização das legislações nos tratados constituintes do Mercosul, na área ambiental não houve progresso.

Sem a devida harmonização legislativa os produtos do bloco continuarão a ser produzidos de acordo com as regulamentações de cada Estado membro, o que inibe o comércio e não protege devidamente o bem ambiental. (utiliza-se as razões de ordem pública como forma arbitrária, a competitividade não é igualitária e o bem ambiental em determinados Estados membros não é protegido). A harmonização da legislação ambiental deverá estar consubstanciada pelos princípios internacionais expressos na declaração do Meio Ambiente de Estocolmo, em 1972, e na Declaração do Rio sobre o Meio Ambiente e o Desenvolvimento de 1992 sob qual se editou a Convenção das Nações Unidas sobre Diversidade Biológica (princípio da precaução com menos requisitos para a sua aplicação).

Há um escalonamento de diretivas ambientais visando a harmonização legislativa. $\mathrm{O}$ primeiro passo será a edição, pelas instituições do Mercosul, de normativas ambientais visando regular a matéria. $\mathrm{O}$ segundo passo será a edição de diretiva pelo $\mathrm{CMC}$ regulando a responsabilidade ambiental com intuito de prevenção e reparação dos danos ambientais.

A consequência desta falta de regulamentação da matéria ambiental no Mercosul é vista no Ótgão de Solução de Controvérsias pela não abordagem desta matéria nas controvérsias entre os Estados membros, ocasionando sérias prejuizos ao ambiente e por consequência a saúde humana. Houve a ocorrência de duas controvérsias importantes com reflexos ambientais: o VI laudo arbitral de 09.01.2002 sobre a proibição pelo Brasil de importação de pneumáticos remoldados procedente do Uruguai e o VII laudo arbitral de 14.11.2002 sobre obstáculos ao ingresso de produtos fitossanitários argentinos no mercado brasileiro. Comentarei o VI laudo arbitral.

O VI laudo arbitral ${ }^{14}$ envolve no objeto da controvérsia a legislação ambiental brasileira. Necessário se faz comentá-la. A política nacional do meio ambiente foi estabelecida pela Lei $6938 / 81$. O seu art. $3^{\circ}$ conceitua o meio ambiente como conjunto de condições, leis, influências e interações de ordem física, química e biológica, que permite, abriga e rege a vida em todas as formas; e dano ambiental como a degradação da qualidade ambiental resultante de atividades que direta e indiretamente prejudiquem a saúde, a segurança e o bem estar da população, criem condições adversas às atividades sociais e econômicas, afetem desfavoravelmente a biota, afetem as condições estéticas ou sanitárias do meio ambiente e lancem matérias ou energia em desacordo com os padrões ambientais estabelecidos. Institui o CONAMA como órgão consultivo e deliberativo para as políticas governamentais ambientais e entre outras funções estabelecer normas padrões compatíveis com o ambiente ecologicamente equilibrado.

${ }^{14}$ Tempesta, Guilhermo. Comentário al Sexto Laudo Arbitral.Mercosur, el Derecho Internacional y el Estoppel:A Proposito del Laudo Arbitral sobre Probibcion de Importacion de Neumaticos "Remoldeados". Revista de Derecho Internacional y del Mercosur. 2002, $\mathrm{n}^{\circ}$ 02, p. 141. 
Dentre muitas resoluções do CONAMA, a nº 258 de 1999 trata da disposição adequada dos pneumáticos inservíveis por responsabilidade das empresas fabricantes e importadoras deste bem. Estabelece de forma progtessiva o equilibrio da disposição correspondentes dos pneus produzidos colocados no mercado e o passivo ambiental já existente com o objetivo de eliminá-lo. Estabelece também a obrigação dos fabricantes e importadores de efetuar a destinação final do bem de forma ambientalmente adequada não permitindo sua disposição em aterros sanitários, mar, rios e queima a céu aberto.

O Ministério da Economia Fazenda e Planejamento, através da portaria n ${ }^{\circ}$ 08/91 proibiu a importação de bens de consumo usados. A portaria $n^{\circ}$ 08/00 da SECEX do Ministério do Desenvolvimento, Indústria e Comércio Exterior proibiu a emissão de licença para a importação de pneumáticos recauchutados e usados para consumo ou matéria-prima classificados na posição 40.12 da Nomenclatura Comum do Mercosul (NCM). Esta portaria foi objeto de contencioso entre Uruguai e Brasil. Após tentativas de negociação entre Uruguai e Brasil, inclusive com a intervenção sem sucesso do GMC, o Uruguai iniciou o procedimento arbitral contra o Brasil por este ter proibido a importação de pneumáticos recauchutados de países membros do Mercosul.

O ponto central da controvérsia do laudo arbitral era se nos bens usados disposto na descrição da portaria 08/91 da DECEX, art. 27, estava incluso os pneumáticos recauchutados. Em nenhum momento do desenrolar da controvérsia foi inserida a questão ambiental. $O$ Tribunal Arbitral Ad Hoc decidiu pela incompatibilidade da normativa proveniente da portaria 08/00 da SECEX do Brasil com as normas do Mercosul, ou seja, medida de efeito equivalente a restrição do comércio recíproco.

O argumento uruguaio que teve mais importância ao julgamento foi a incidência do princípio do Estoppel, pois houve um tráfico comercial de importações pelo Brasil de pneumáticos recauchutados provenientes do Uruguai entre 1991 à 2000 criando uima situação jurídica de serem considerados atos lícitos entre as partes. Foi gerado uma expectativa legítima aos agentes uruguaios em função da atuação dos órgãos públicos brasileiros em considerarem lícitas as importações dos pneus recauchutados (pareceres de aprovação da DILEG- Divisão da Legislação Nacional, da COANA- Coordenação Geral do Sistema Aduaneiro, Receita Federal e CONAMA. Houve criação de uma relação jurídica que por sua vez deriva obrigações em obediência ao princípio da boa fé.

Os princípios de Direito Internacional são fonte de interpretação jurídica e previsto no Protocolo de Brasília para a solução de controvérsias no art. 19 e previsto também no art. 38 do Estatuto da Corte Internacional de Justiça.

A partir da decisão do laudo arbitral houve a edição da portaria 02/02 do Ministério do Desenvolvimento e Comércio Exterior autorizando o licenciamento de importação de pneumáticos remoldados procedentes dos Estados partes do Mercosul segundo normas técnicas para o produto do INMETRO. Houve portanto a acatamento pelo governo brasileiro da decisão ocorrida no laudo arbitral. Contudo a portaria está sendo contestada pelos Tribunais brasileiros diante das normas ambientais nacionais. 


\section{CONCLUSÃO}

A responsabilidade civil ambiental é instituto jurídico que visa restaurar o bem ambiental mas também atuar de forma inibitória prevenindo o acontecimento do dano ambiental. Esta duas perspectivas estão previstas na proposta de diretiva sobre responsabilidade ambiental formulada pela comissão das comunidades européias.

A previsão de diretrizes ambientais no Mercosul permite a harmonização das legislações nacionais sobre este bem de forma a proteger devidamente o meio ambiente não o utilizando como meio disfarçado de discriminação do comércio internacional dos Estados membros desta organização regional de cooperação econômica.

Assim como no Mercosul o Nafta também não contém normas ambientais regulando a matéria. Cada país aplica suas próprias regras devendo ser justas e imparciais não sendo mais restritivas que o necessário. Esta medida de não regulação é justificada pela necessidade que cada Estado membro tem de atuar conforme suas características específicas ambientais. (e podemos adicionar também conforme seu interesse e neste caso o bem ambiental não é visto como um patrimônio da humanidade).

A União Européia é o exemplo a ser seguido pela suas formulações de diretivas ambientais e pela disposições contidas no projeto de diretiva sobre responsabilidade ambiental. Tem-se o bem ambiental como patrimônio da humanidade imbuindo responsabilidades Estatais e de agentes nacionais na restauração do meio ambiente. Os tratados constitutivos no direito primário permitem aos Estados proteger o bem ambiental conforme as características de seu território mesmo que com estas medidas promovam a inibição da circulação de mercadorias.

O Mercosul tem um caminho árduo a percorrer no sentido de entender que parte de seus Estados membros devam ter ajuda financeira e tecnológica para se adequar a proteção ambiental previstas nas legislações brasileiras.

A legislação ambiental brasileira poderá ser exemplo para a harmonização das leis nacionais dos demais Estados, porém, como já mencionado, deverá este país contribuir para esta harmonização com ajuda tecnológica e profissional aos demais Estados.

A demora desta harmonização implica em prejuízo ambiental no âmbito do Mercosul pela degradação ambiental permitida e dificulta aos Estados comercializarem suas mercadorias de forma igualitária pela não internalização dos custos ambientais a fabricação do bem objeto de mercancia ou pela ocorrência de discriminação arbitrária disfarçada, já que a proteção do bem ambiental não é o resultado visado pelo Estado importador e sim a proteção da ineficiência empresarial da fabricação de produtos nacionais. 


\section{REFERÊNCIAS BIBLIOGRÁFICAS}

ANTUNES, Paulo de Bessa. Dano Ambiental: Uma abordagem conceitual. Rio de Janeiro: Lumen Juris.2000.

BASSO, Maristela. Org. Mercosul . Seus efeitos jurídicos, Econômicos e Políticos nos Estados-Membros: Porto Alegre: Livraria Advogado,1997.

DALL'AGNOL JUNIOR, Antônio Janyr. Distribuição Dinâmica dos ônus Probatórios. Revista Tribunais, Jun. 2001.

DIAS, José Eduardo de Oliveira Figueiredo. Tutela Ambiental e Contencioso Administrativo. Coimbra: Universidade Coimbra. 1997.

KLOR, Adriana Dreyzian, PIMENTEL, Luiz Otávio, KEGEL, Patricia Luíza, BARRA, Welber. Soluções de Controvérsias. OMC, União Européia e Mercosul. Rio de Janeiro: Konrad-Adenauer-Stiftung,2004.

LEITE, José Rubens Morato. Dano Ambiental: do indivíduo ao coletivo extrapatrimonial. São Paulo: Revista dos Tribunais.2000.

LEITE, José Rubens Morato, AYALA, Patryck de Araújo. Direito Ambiental na Sociedade de Risco. Rio de Janeiro: Forense Universitária.2002.

LIVRO BRANCO SOBRE RESPONSABILIDADE AMBIENTAL. Bruxelas: Comissão das Comunidades Européias, 9.2.2000, COM.

MARTÍN, Araceli Mangas, NOGUERAS, Diego J. Liñán. Instituciones y Derecho de la Unión Europea. Madrid: Tecnos, 2002.

MAGARIÑOS, Gustavo. Comércio e Integracion: mundo-continente-región. Montevideo: Fundação de Cultura Universitária,Tomo I, 1994.

SELMA, Maria Ferreira Lemes. O Sistema de Solução de Controvérsias no "North American Free Trade Agreement” in Guerra Comercial ou Integração Mundial pelo Comércio? : a OMC e o Brasil/ Paulo Borba Casella, Araminta de Azevedo Mercadante coord.-S.P: LTr, 1998.

TEMPESCA, Guilhermo. Comentario al Sexto Laudo Arbitral. Mercosur, el Derecho Internacional y el Estoppel: A Proposito del Laudo Arbitral sobre Prohibicion de Importacion de Neumaticos Remoldeados. Revista de Derecho Internacional y del Mercosur. La Ley Ano 6, N², 2002.

THIEFFRY, Patrick. Direito Europeu do Ambiente. Lisboa: Editions Dalloz, Tradução Maria Fernanda Oliveira,1998.

TRATADO DE LA UNIÓN EUROPEA: Tratados constitutivos de las comunidades europeas y otros actos básicos de derecho comunitario, $7^{\circ}$ ed. Madri: Tecnos.1999.

VALLOTTON, Nicole Stoffel. La Prohibicion de restricciones a la libre circulación de mercancás en la comunidade europea. Madri: Dykinson.2000.

ZAELKE, Durwood, ORBUCH Paul, HOUSMANN Robert. Comércio Internacional y Médio Ambiente. Derecho, Economia y Política. Buenos Aires: Espacio Editorial, Trad. Eugenia Bec, 1995. 